\title{
Biochar-carrying hydrocarbon decomposers promote degradation during the early stage of bioremediation
}

\author{
Polina Galitskaya, Leisan Akhmetzyanova, and Svetlana Selivanovskaya \\ Institute of Environmental Sciences, Kazan Federal University, Kazan, Russia \\ Correspondence to: Polina Galitskaya (gpolina33@yandex.ru)
}

Received: 14 July 2016 - Published in Biogeosciences Discuss.: 25 July 2016

Revised: 29 September 2016 - Accepted: 30 September 2016 - Published: 17 October 2016

\begin{abstract}
Oil pollution is one of the most serious current environmental problems. In this study, four strategies of bioremediation of oil-polluted soil were tested in the laboratory over a period of 84 days: (A) aeration and moistening; (B) amendment with $1 \%$ biochar $(w / w)$ in combination with A; amendment with $1 \%$ biochar with immobilized Pseudomonas aeruginosa (C) or Acinetobacter radioresistens (D) in combination with A. All strategies used resulted in a decrease of the hydrocarbon content, while biochar addition (B, C, D strategies) led to acceleration of decomposition in the beginning. Microbial biomass and respiration rate increased significantly at the start of bioremediation. It was demonstrated that moistening and aeration were the main factors influencing microbial biomass, while implementation of biochar and introduction of microbes were the main factors influencing microbial respiration. All four remediation strategies altered bacterial community structure and phytotoxicity. The Illumina MiSeq method revealed 391 unique operational taxonomic units (OTUs) belonging to 40 bacterial phyla and a domination of Proteobacteria in all investigated soil samples. The lowest alpha diversity was observed in the samples with introduced bacteria on the first day of remediation. Metric multidimensional scaling demonstrated that in the beginning and at the end, microbial community structures were more similar than those on the 28th day of remediation. Strategies A and B decreased phytotoxicity of remediated soil between 2.5 and 3.1 times as compared with untreated soil. C and D strategies led to additional decrease of phytotoxicity between 2.1 and 3.2 times.
\end{abstract}

\section{Introduction}

Soil pollution with petroleum is one of the most serious problems nowadays. Despite the fact that many methods of remediation of petroleum pollution have been proposed, development of effective and environmentally friendly methods of hydrocarbon removal from soil ecosystems is still highly required. As such a method, many authors propose bioremediation, which is easily implemented into practice, costeffective, and environmentally relevant (Agnello et al., 2015; Kauppi et al., 2011; Suja et al., 2014; Wu et al., 2016). The soil microbiota provides several ecosystem services, such as organic compounds' decomposition, including the degradation of organic toxicants (Beesley et al., 2011). Currently, two strategies of bioremediation are actively used - biostimulation and bioaugmentation (Kauppi et al., 2011; Wu et al., 2016). The first strategy includes activities that stimulate the indigenous microflora of oil-polluted site; the second one introduces active microbial decomposers into the remediated site. Many authors report high efficiency of biostimulation and low additional benefit from bioaugmentation (Kauppi et al., 2011; Taccari et al., 2012; Tahhan et al., 2011). Some authors report that the best treatment method of oil-polluted soils is a combination of biostimulation and bioaugmentation (Wu et al., 2016).

Biochar, a product of thermic degradation of organic matter under anaerobic conditions (pyrolysis), is often used for soil quality improvement (Beesley et al., 2011; Kuppusamy et al., 2016; Lehmann et al., 2011; Liu et al., 2016; Tang et al., 2013). Biochar has several positive effects on soil: it leads to carbon sequestration and, consequently, decreased $\mathrm{CO}_{2}$ emission rates, increases soil porosity and water-holding capacity, and improves soil pH (Awad et al., 2012; Kuśmierz et al., 2016; Lehmann and Joseph, 2009). Because of its high 
surface area and porosity, biochar can be a good substrate for colonization and active functioning of soil-indigenous microflora (Quilliam et al., 2013). Therefore, besides abiotic factors, biochar addition may change the structure of the microbial community, enzyme activity, decomposition of carbon substrates, and cycling of other elements in soils (Kuzyakov et al., 2009; Lehmann et al., 2011; Rutigliano et al., 2014; Tang et al., 2013; Wang et al., 2015). Biochar can absorb organic and inorganic compounds on its surface. According to several authors, this is an advantage as sorption decreases liability and availability of toxicants in soils (Beesley et al., 2010; Lu et al., 2015), leading to a decrease of phytotoxicity (Butnan et al., 2015). Thus, the absorption ability of biochar is used for bioremediation of soils polluted by petroleum hydrocarbons such as alkanes, polycyclic aromatic hydrocarbons, and asphaltenes (Beesley et al., 2011; Qin et al., 2013). The effect of biochar on oil-polluted soils is different and dependent e.g., on doses and time of use, type of biochar (initial substrates and method of preparation), and soil quality (Domene et al., 2015; Jones et al., 2012; Lehmann et al., 2011).

Biochar can be introduced into the soil, not only as a soil conditioner, but also as a carrier of microbial inoculates. Several authors agree that the influence of biochar on immobilized microbes is different and depends on the biochar itself as well as on the microorganisms; therefore, the decision concerning its use as a carrier should be made individually in each particular case. In the literature, results about immobilization effects of biochar on rhizosphere and symbiotic microbes that promote plant growth are presented (Lehmann et al., 2011). Poor data concerning the use of biochar for immobilization of hydrocarbon degrading microbes can be found in literature (Qin et al., 2013). However, biochar with immobilized hydrocarbon degraders can potentially be an efficient tool of oil-polluted soil remediation.

The objective of this study was to estimate the efficiency of biochar as a biostimulating tool as well as a carrier for hydrocarbon-degrading bacteria for the remediation of oilpolluted soil in a laboratory experiment. Two bacterial strains isolated previously from oil-polluted soils on the basis of their high degrading potential were used for biochar inoculation. Hydrocarbon content, phytotoxicity, microbial respiration and biomass, as well as bacterial community structure were used as parameters for efficiency estimation of the bioremediation methods used.

\section{Material and methods}

\subsection{Contaminated soil and biochar}

Oil-contaminated soil was sampled in the area of a 1-year-old oil spill situated close to Niznekamsk (Tatarstan Republic, Russia). Prior to sampling, plants were removed and soil was sampled to a depth of $10 \mathrm{~cm}$. Five replicates were sampled, and one representative sample was prepared. The sample was air-dried, sieved ( $2 \mathrm{~mm}$ mesh size), and stored at $4{ }^{\circ} \mathrm{C}$ in the dark for further use. The soil showed the following characteristics: $40.5 \%$ sand, $54.1 \%$ silt, and $5.4 \%$ clay (as revealed by laser diffraction according to ISO 13320:2009 and ISO/TS 17892-4:2004); $\mathrm{pH}-6.5$ (as revealed by ISO 10390:2005 method); organic carbon content $-9.1 \%$ (as revealed by ISO 14235:1998 method); total nitrogen content $-0.15 \%$ (as revealed by ISO 11261:1995 method); hydrocarbon content as revealed by infrared spectroscopy $-4.7 \%$ (of this, $15.5 \%$ saturated hydrocarbon, $23.4 \%$ aromatics, $58.4 \%$ resins, and $2.7 \%$ asphaltenes).

Biochar used in the study was obtained by slow pyrolysis of birch wastes at $450{ }^{\circ} \mathrm{C}$. Immediately after preparation and cooling, biochar was sampled from the pyrolysis chamber under sterile conditions. Biochar characteristics are presented in Table S1 in the Supplement.

\subsection{Immobilization of microbes on biochar}

Two strains of microorganisms able to actively degrade hydrocarbons and previously isolated from oil-polluted soils sampled in the Tatarstan Republic (Russia) were used - Pseudomonas aeruginosa and Acinetobacter radioresistens. Before immobilization on biochar, the strains were cultivated for 7 days at $28^{\circ} \mathrm{C}$ and with a rotation of $130 \mathrm{rpm}$ on liquid medium with the following composition: $\left(\mathrm{NH}_{4}\right)_{2} \mathrm{SO}_{4}\left(1.0 \mathrm{~g} \mathrm{~L}^{-1}\right), \mathrm{MgSO}_{4}\left(0.2 \mathrm{~g} \mathrm{~L}^{-1}\right), \mathrm{KH}_{2} \mathrm{PO}_{4}$ (3.0 $\left.\mathrm{g} \mathrm{L}^{-1}\right), \mathrm{Na}_{2} \mathrm{HPO}_{4}\left(4.5 \mathrm{~g} \mathrm{~L}^{-1}\right) ; 2 \%$ of oil $(v / v)$ was used as a sole carbon source. For immobilization, biochar was plunged into the bacterial culture, stored for 1 day, and then used for further bioremediation. The final concentration of bacterial cells on biochar was equal to $5-9 \times 10^{8} \mathrm{CFU}$. All the manipulations with biochar before remediation were conducted under sterile conditions.

For screening of the biochar surface as well as the immobilized bacteria, the universal analytical complex of scanning autoemission microscopy, Merlin (Carl Zeiss, Germany), was used. Before scanning, biochar samples were dewatered in $1 \%$ glutaraldehyde solution and an ascending alcohol series.

\subsection{Experimental design}

The oil-polluted soil sample was treated using four different methods for 84 days. For each treatment method, three incubation containers with $1 \mathrm{~kg}$ of soil were prepared. Soil samples were brought up to $60 \%$ water-holding capacity. We used the following four treatment methods: (A) soil with no biochar, (B) soil amended with biochar $1 \%(w / w)$, (C) soil amended with biochar $1 \%(w / w)$, which was previously inoculated with Pseudomonas aeruginosa, and (D) soil amended with biochar $1 \%(w / w)$, which was previously inoculated with Acinetobacter radioresistens. Once a week, each remediation trial was mixed for aeration, and water con- 
Table 1. Treatments of oil-polluted soil used in the study.

\begin{tabular}{|c|c|c|c|c|c|}
\hline Treatment and method of remediation & A & B & $\mathrm{C}$ & $\mathrm{D}$ & $\mathrm{E}$ \\
\hline Mixing and moistening figure & + & + & + & + & - \\
\hline Amendment with biochar $1 \%(w / w)$ & - & + & + & + & - \\
\hline Amendment with biochar $1 \%(w / w)$, which was previously inoculated with Pseudomonas aeruginosa & - & - & + & - & - \\
\hline Amendment with biochar $1 \%(w / w)$, which was previously inoculated with Acinetobacter radioresistens & - & - & - & + & - \\
\hline
\end{tabular}

tent was restored by weighing. (E) A variant without any treatment was used as a control (Table 1).

The remediated soil samples were taken on days $1,7,14$, $28,42,56,70$, and 84 of the study. On each sampling day, 30 samples $(5$ variants of treatments $(A-E) \times 3$ containers for each treatment $\times 2$ samples from each container) were examined; each sample was obtained by mixing together three soil cores. Soil microbial biomass carbon and respiration as well as phytotoxicity were estimated in fresh soil samples immediately after sampling. Hydrocarbon content was measured in air-dried soil. DNA for further analysis of bacterial diversity was extracted from fresh soil and stored at $-20^{\circ} \mathrm{C}$.

\subsection{Chemical and biological analyses}

Hydrocarbon content was estimated using infrared spectrometry with an AN-2 analyzer (LLC Neftehimavtomatika-SPb, Russia). Basal respiration activity of soil was determined on the basis of $\mathrm{CO}_{2}$ emission from soil during $24 \mathrm{~h}$, according to ISO 16072 (2002). Soil microbial biomass carbon was determined by fumigation of the samples with $\mathrm{C}_{2} \mathrm{H}_{5} \mathrm{OH}$-free $\mathrm{CHCl}_{3}$ and extraction with $0.5 \mathrm{M} \mathrm{K}_{2} \mathrm{SO}_{4}$. The extracted $\mathrm{C}$ content was determined by bichromate oxidation in accordance with ISO 14240-2 (1998). Phytotoxicity was estimated using oat plants (Avena sativa) via the contact method according to ISO 11269-1 (2012) and ISO 11269-2 (2012). Germination index (GI) was calculated as described by Zucconi et al. (1981) and used as a phytotoxicity parameter. GI (\%) combined measurement of relative seed germination and relative root elongation.

\subsection{Quantitative $\leq \mathrm{CR}$ and next generation sequencing}

DNA was extracted using the FastDNA ${ }^{\circledR}$ SPIN Kit for Soil (Bio101, Qbiogene, Germany), according to the instructions provided, and purified using QIAquick PCR Purification Kit (Quiagen, Germany). After a quality check on agarose gel, $16 \mathrm{~S}$ rDNA genes were amplified by real-time polymerase chain reaction (PCR) in triplicate on a BioRad CFX-96 cycler (BioRad, Munich, Germany). The $25 \mu \mathrm{L}$ reaction mixture contained $5 \mathrm{U}_{\mu} \mathrm{L}^{-1}$ SynTaq polymerase, $10 \times$ buffer with SYBR Green, $10 \mathrm{mM}$ dNTPs each, $10 \mu \mathrm{M}$ primer $(16 \mathrm{~S}$ 984f and 1378r) each, and $1 \mu \mathrm{L}$ of DNA template. The amplification protocol was as follows: initial denaturation at $95^{\circ} \mathrm{C}$ for $5 \mathrm{~min}$, followed by 39 three-step cycles at $62-60{ }^{\circ} \mathrm{C}$ for $45 \mathrm{~s}, 95^{\circ} \mathrm{C}$ for $15 \mathrm{~s}$, and $72^{\circ} \mathrm{C}$ for $30 \mathrm{~s}$. The standard curves for bacteria were generated using serial DNA dilutions of DNA of Bacillus pumilus. The concentration of template DNA and amplicons was quantified on the Qubit fluorimeter (Invitrogen, USA) using Quant-iT ${ }^{\mathrm{TM}}$ dsDNA HighSensitivity Assay Kit (Thermo Fisher, USA).

Preparation of the libraries was performed in accordance with the $16 \mathrm{~S}$ Metagenomic Sequencing Library Preparation Protocol recommended for Ilumina MiSeq. The first round of amplification of V3-V4 region of 16sRNA gene was performed on DNA Engine Tetrad ${ }^{\circledR} 2$ cycler (BioRad, Germany) with specific primers A (TCGTCGGCAGCGTCAGATGTGTATAAGAGACAGCCTACGGGNGGCWGCAG) and B (GTCTCGTGGGCTCGGAGATGTGTATAAGAGACAGGACTACHVGGGTATCTAATCC), using the following protocol: initial denaturation for $3 \mathrm{~min}$ at $95^{\circ} \mathrm{C}$, 27 cycles of $30 \mathrm{~s}$ at $95^{\circ} \mathrm{C}, 30 \mathrm{~s}$ at $55^{\circ} \mathrm{C}$, and $30 \mathrm{~s}$ at $72^{\circ} \mathrm{C}$; and final extension for $5 \mathrm{~min}$ at $72^{\circ} \mathrm{C}$. Further purification of amplicons was performed with the Agencourt AMPure XP purification kit (Beckman Coulter, USA). The second round of amplification was performed for double indexing of samples using the same cycle parameters with primers presented in Table S2.

The library obtained was validated on Bioanalyzer 2100 using the Agilent DNA $1000 \mathrm{Kit}$ (Agilent, USA) and quantified on the Qubit Fluorometer (Invitrogen, USA) using the Quant-iT ${ }^{\mathrm{TM}}$ dsDNA High-Sensitivity Assay Kit (Thermo Fisher, USA). Purified amplicons were pooled at equal concentration. Further preparation of samples and sequencing were performed using the MiSeq Reagent Kit v2 (300 cycles) on the MiSeq device (Illumina, USA) according to the manufacturer's protocol.

After the sequencing process, previously added adapter sequence was removed, and then samples were determined using index sequence by means of Illumina BaseSpace software (www.basespace.illumina.com). QIIME platform (Caporaso et al., 2010) was used for further analysis of the sequence data. After the quality filtering step $(Q<20)$, chimeras were removed using the usearch61 algorithm. Operational taxonomic units (OTUs) clustering against the Greengenes database (August 2013 release) was done using the implemented USEARCH pipeline (Edgar, 2010) with a $97 \%$ sequence identity threshold. Only OTUs being represented by at least five reads were kept. Taxonomic classification was performed using the implemented RDP classifier with PyNAST (Wang et al., 2007). 


\subsection{Statistical analysis}

Sampling and chemical analyses were carried out in triplicate, biological analyses in five replicates in order to decrease the experimental errors and to increase the experimental reproducibility. All results were expressed on an airdried soil basis. The data from the experiment were statistically processed on a computer using Origin 8.5 (OriginLab, Northampton, USA). The confidence of data generated in the present investigations has been analyzed by standard statistical methods to determine the mean values and standard errors (SEs). The means were compared using Fisher's least significant difference at $\alpha=0.05$. The values in figures and tables were expressed as mean $\pm \mathrm{SE}$ of the corresponding replicates.

Alpha and beta diversities of bacterial communities were estimated using the Vegan package of the R software (R Core Development Team, 2015). Alpha diversity was expressed using several indices: Shannon-Weaver (H index) and Simpson (D index) indices were calculated according to Shannon and Weaver (1963) and Simpson (1949), respectively; the simple index (I index) was calculated as the number of OTUs revealed by Illumina sequencing. To visualize the differences in microbial communities, metric multidimensional scaling (MDS) plots were created, where matrices of band abundance were assembled, and similarity matrices were calculated according to the Bray-Curtis coefficient (Faith et al., 1987).

\section{Results and discussion}

Two bacterial strains $-P$. aeruginosa and A. radioresistens - were immobilized on biochar. These strains were previously isolated from oil-polluted sites and used in this study because of their high efficiency in hydrocarbon decomposition (Rocha et al., 2013; Tang et al., 2010; Wu et al., 2016). Figure 1 shows the images confirming inoculation of biochar by the two strains.

Initial biochar as well as biochar with immobilized microbes was introduced to the soil at an amount of $1 \%$. A comparable quantity of biochar for soil conditioning was used in both lab-scale and field-scale experiments in other studies (Qin et al., 2013; Rutigliano et al., 2014; Smith et al., 2010); some authors used quantities of 5 to $10 \%$ biochar (Bhaduri et al., 2016; Xu et al., 2016).

In the process of bioremediation that lasted for 84 days, hydrocarbon content decreased in all the variants, except the control, as presented in Fig. 2. The maximal decrease rate was observed during the first 14 days, but this rate was different for different variants. Thus, on day 14 , decrease of hydrocarbon content was estimated to be $13,42,49$, and $53 \%$ of the initial content $\left(47 \mathrm{~g} \mathrm{~kg}^{-1}\right)$ in the variants $\mathrm{A}, \mathrm{B}, \mathrm{C}$, and $\mathrm{D}$, respectively. However, at the end of the experiment, the decrease of amounts of hydrocarbon in the four variants did not differ significantly; these were $56,59,66$, and $66 \%$ of the initial content, respectively $(p \leq 0.05)$.

In variant $\mathrm{A}$, which was moistened and aerated, hydrocarbon decomposition reached a plateau on day 42 , when the content was $23 \mathrm{~g} \mathrm{~kg}^{-1}$. Petroleum hydrocarbons may not fully be used by microbes since they contain a lot of recalcitrant compounds (Alexander, 1995; Atlas, 1995). Many authors agree that intensive decomposition of petroleum hydrocarbons occurs in the first 15-50 days; after this, the biodegradation rate decreases (Al-Mutairi et al., 2008; Beškoski et al., 2011; Jørgensen et al., 2000; Liu et al., 2009; Marin et al., 2005). Hydrocarbon decrease rates in our study are in line with those presented by other researchers. For example, Jørgensen et al. (2000) observed a 58-66\% decrease of hydrocarbon content during 35 days with an initial oil concentration of $2.4 \mathrm{~g} \mathrm{~kg}^{-1}$, and Beškoski et al. (2011) found a $60 \%$ decrease in 150 days with an initial concentration of $5.2 \mathrm{~g} \mathrm{~kg}^{-1}$. The decrease of hydrocarbon content in variant A was due to the soil-indigenous microflora that becomes more active because of optimal environmental conditions in the study. Indeed, aeration and moistening were widely described as effective remediation tools (Gumerova et al., 2013; Jørgensen et al., 2000; Selivanovskaya et al., 2012; Suja et al., 2014).

As mentioned above, in variants $\mathrm{B}, \mathrm{C}$, and $\mathrm{D}$, hydrocarbon content decreased more rapidly than in $\mathrm{A}$ and reached a plateau on day 14. Therefore, at the beginning of the remediation phase (up to day 42), significant differences in hydrocarbon contents between variant $\mathrm{A}$ and the other variants were observed. The additional accelerative effect of biochar on hydrocarbon decomposition is most likely connected with the fact that labile components of biochar are good sources of organic matter and inorganic nutrients for microbes (Lehmann et al., 2011). These components can be co-substrates that initiate hydrocarbon metabolism. Additionally, biochar can adsorb toxic compounds, such as polycyclic aromatic hydrocarbons, and therefore decrease soil toxicity (Beesley et al., 2010; Qin et al., 2013; Rutigliano et al., 2014). Our results are in agreement with a study by Qin et al. (2013) who demonstrated that biochar stimulated hydrocarbon decomposition in oil-polluted soil. The authors observed that in addition to stimulating degradation of bioavailable compounds, such as alkanes and aromatics, biochar may improve decomposition of recalcitrant compounds, such as polar oil fractions (Qin et al., 2013). From a practical point of view, the acceleration effect of biochar on hydrocarbon content decrease may be used in cases when time is a significant factor, e.g., when oil spills occur in regions with cold climates and soil remediation needs to be performed within a limited period of time.

Immobilization of microbes on biochar $(\mathrm{C}$ and $\mathrm{D}$ variants) resulted in slightly different hydrocarbon decomposition rates for 28 days compared with variant $\mathrm{B}$. We observed no further significant differences between the three variants $(p \leq 0.05)$. Bioaugmentation as a method of biore- 
(a)

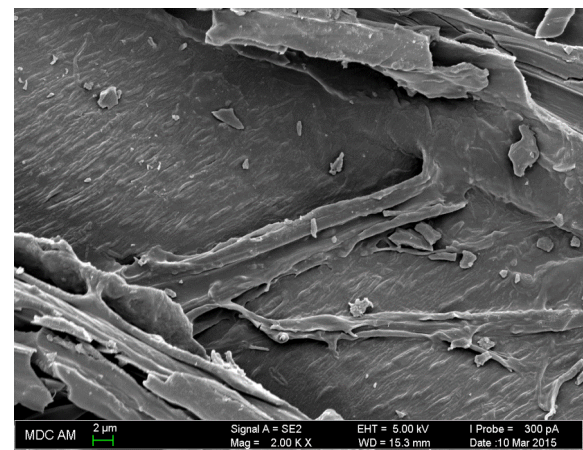

(c)

(e)

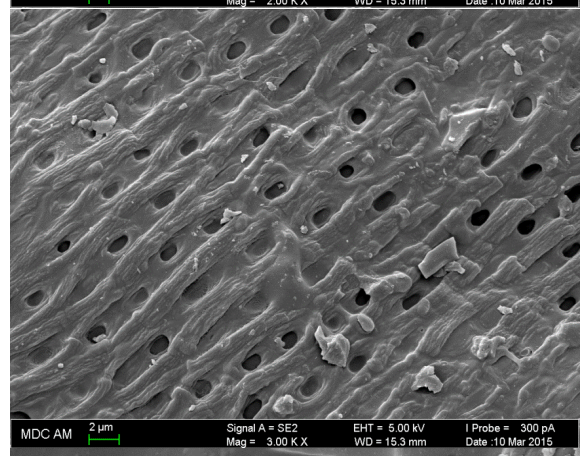

(g)
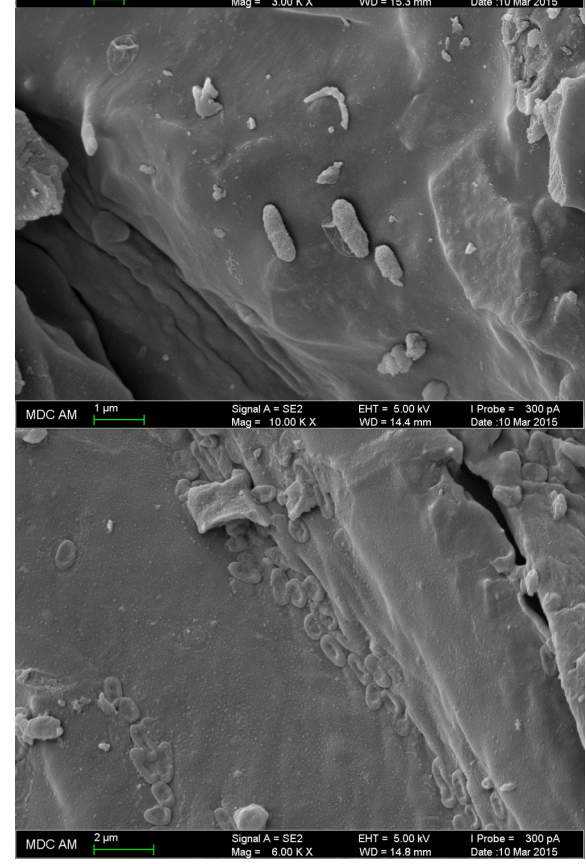

(b)

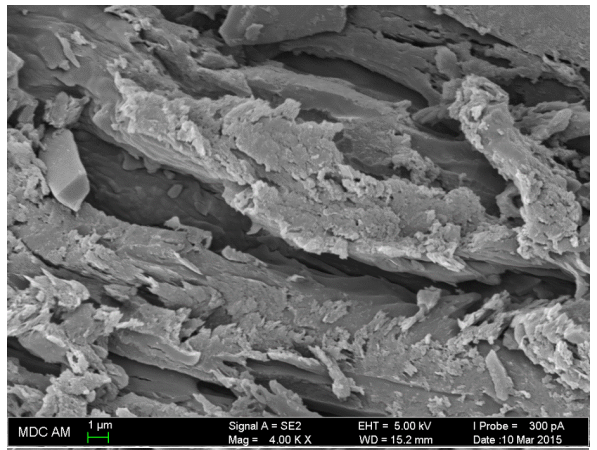

(d)

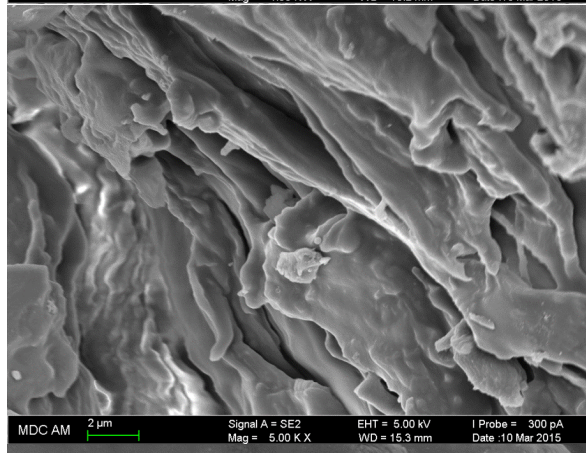

(h)
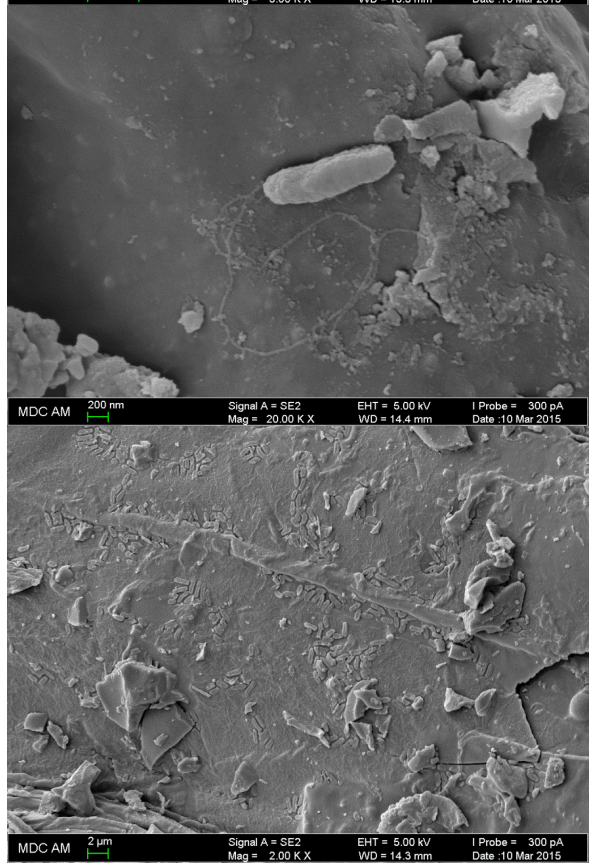

Figure 1. Scanning electron microscope images of initial biochar (a-d), biochar with immobilized cells of $P$. aeruginosa (e, f), and biochar with immobilized cells of $A$. radioresistens $(\mathbf{g}, \mathbf{h})$.

mediation that includes introduction of microbes with specific abilities is widely discussed in the scientific literature and compared with biostimulation. Previous studies reported both positive effects of bioaugmentation as well as no effects (Kauppi et al., 2011; Liu et al., 2009; Tahhan et al., 2011). Wu et al. (2016) showed that the introduction of Acinetobacter $s p$. is useful in the early stages of remediation, whereas biostimulation is a more effective tool. Suja et al. (2014) demonstrated that for high decomposition activity of bacterial consortia containing Pseudomonas sp., Acinetobacter $s p$., and Rhodococcus sp. isolated from oil-polluted soil, effectiveness was higher in combination with biostimulation. Nikolopoulou et al. (2013) found that indigenous microbial degraders in combination with lipophilic nutrients are effective for rapid clean-ups of oil spills. Authors who did not observe positive effects of bioaugmentation explain this by the 


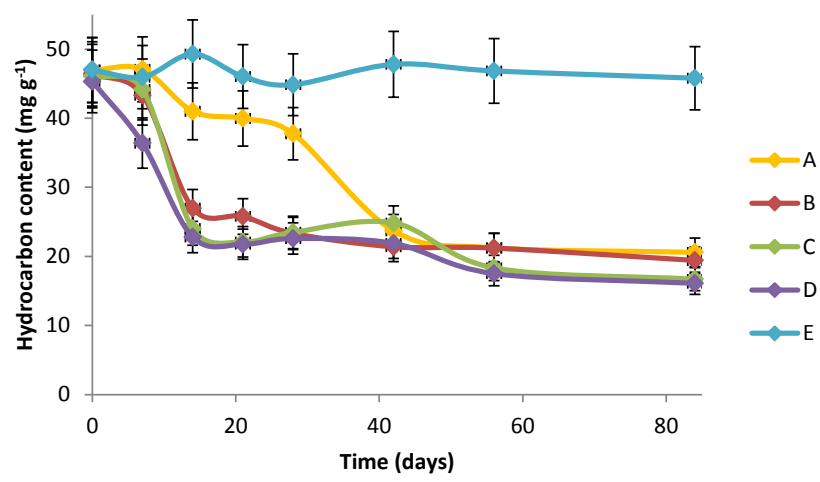

Figure 2. Changes of hydrocarbon content in remediated soil (A - soil that was moistened and aerated, B - soil that was moistened, aerated, and amended with $1 \%$ biochar, $\mathrm{C}$ - soil that was moistened, aerated, and amended with $1 \%$ biochar with P. aeroginosa, D - soil that was moistened, aerated, and amended with $1 \%$ biochar with A. radioresistens, $\mathrm{E}$ - soil without treatment).

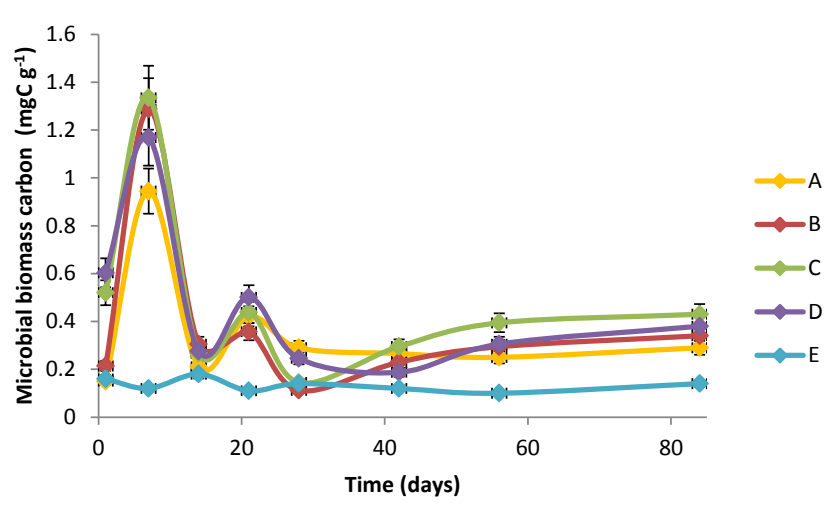

Figure 3. Changes of microbial biomass carbon levels in remediated soil (A, B, C, D, E - as in Fig. 2).

low survival rates and changes of the destructive ability of introduced microbes. These microbes are preliminarily cultivated on cultural media in favorable conditions and subject to stress when introduced into the environment (Tahhan et al., 2011). From this point of view, the use of biochar is a carrier that, as described in our study, may help to overcome this problem.

Since hydrocarbon degradation is driven by microorganisms, integral indexes of the microbial community state may be useful to assess the efficiency of the remediation process. Apart from this, oil components and metabolites produced during bioremediation may influence the functioning and structure of microbial communities. Negative impacts on the microbial community may cause alteration of nutrient cycles and degradation of soil quality and vegetation growth. Soil microbial respiration, biomass, and other parameters can provide valuable information about the presence and activity of microorganisms in remediated soil (Tang et al., 2011, 2012; Tejada et al., 2008).
Results of estimation of microbial biomass carbon during bioremediation are presented in Fig. 3. Microbial biomass is an important component of soil organic matter; it is very labile and sensitive to environmental changes (Demisie et al., 2014; Labud et al., 2007). In the non-treated variant E, microbial biomass carbon level was consistently low (0.10$0.18 \mathrm{mg} \mathrm{g}^{-1}$ ). Comparable data were presented by other researchers for soil contaminated with $5-10 \%$ of oil (Labud et al., 2007) and $5 \%$ of gasoline (Tejada et al., 2008).

Aeration and moistening (variant A) led to an approximately 8 -fold increase of microbial biomass carbon on day 7. This may be explained by an improvement of the conditions for indigenous microbes. Similarly, other authors have observed increased microbial biomass levels during remediation of soil-polluted with 5-10\% oil (Marin et al., 2005). From day 7, microbial biomass carbon level decreased in variant $\mathrm{A}$, but was still higher than in variant $\mathrm{E}$ during the duration of the experiment.

The level of microbial biomass carbon in variant $\mathrm{B}$ was similar to that in variant $\mathrm{A}$. In the literature, a wide spectrum of responses of soil microbial biomass carbon to biochar is presented. For example, Demisie et al. (2014) did not observe any effects on microbial biomass of biochar addition in doses of 1 and $2 \%$. Xu et al. (2016) reported no effects of biochar added to soil in doses lower than $8 \%$. Chan et al. (2008), Durenkamp et al. (2010), and Kuppusamy et al. (2016) did not observe any effect either, stating that biochar may even inhibit microbes because of its ability to alter soil $\mathrm{pH}$ and electric conductivity, to liberate toxicants, including heavy metals and polyaromatic hydrocarbons, and to provide excess of nutrients. In contrast, other authors reported a stimulating effect of biochar on soil microbial biomass, stating that biochar provides a good habitat for beneficial microbes (Kuppusamy et al., 2016) by adsorbing soluble organic carbon, which is a substrate for the microflora (Beesley et al., 2011).

Levels of microbial biomass carbon in variants $\mathrm{C}$ and $\mathrm{D}$ did not differ significantly from those in variants $\mathrm{A}$ and $\mathrm{B}$ $(p \leq 0.05)$. In all four variants, the values were higher than in the control. Apart from that, trends of microbial biomass carbon dynamics were similar in variants $A$ to $D$, suggesting that neither biochar addition nor the introduction of degraders strains immobilized on biochar have higher effects than aeration and moistening.

The intensity of $\mathrm{CO}_{2}$ production is one of the most important and most widely used microbial indexes of soil quality, reflecting metabolic activity of microbes and their responses to pollution or other stressful factors as well as to stimulation (Domene et al., 2015; Ros et al., 2010; Tejada et al., 2008). $\mathrm{CO}_{2}$ emissions from soil during bioremediation are presented in Fig. 4. Minimal respiration activity of soil microbes was found in the untreated control $(0.14-0.26 \mathrm{mg} \mathrm{C}$ $\mathrm{CO}_{2} \mathrm{~g}^{-1} 24 \mathrm{~h}^{-1}$ ). Aeration and moistening in variant $\mathrm{A}$ led to a 1.7-fold increase of microbial respiration. For three variants, B, C, and D, increase of microbial respiration was ob- 


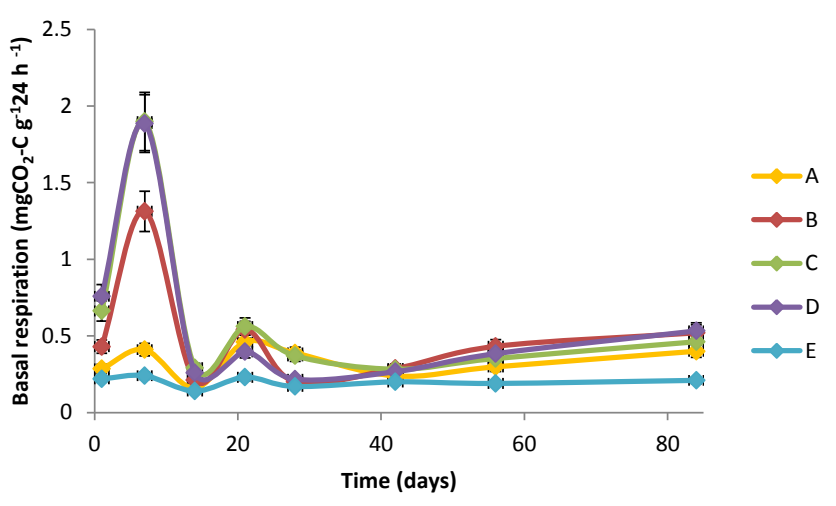

Figure 4. Changes of microbial respiration in remediated soil (A, B, C, D, E- as in Fig. 2).

served at the beginning of remediation, while the respiration peaks in variants $\mathrm{C}$ and $\mathrm{D}$ with introduced microbes were more significant. Thus, on day 7 , microbial respiration in variant $B$ was 2.6 times higher and in variants $C$ and D, 3.6 times higher than in the control. Further, respiration activity in the three variants decreased, and on day 28 , no differences between these three and variant A were observed.

Previous studies have described a short-term increase of microbial respiration after biochar addition (Domene et al., 2015; Lehmann et al., 2011; Rutigliano et al., 2014; Smith et al., 2010; Xu et al., 2016). For example, Smith et al. (2010) demonstrated that microbial respiration increased for 6 days after the addition of biochar obtained by pyrolysis at $500^{\circ} \mathrm{C}$. Rutigliano et al. (2014) showed an increase in substrateinduced respiration as well as specific substrate activity (to succinic, citric, ascorbic, gluconic, ketoglutaric, and fumaric acids) for 3 months after biochar addition at doses of 30 and $60 \mathrm{tha}^{-1}$. The authors explain the temporary increase of respiration by direct use of biochar components as a substrate (e.g., volatile organic compounds produced in the process of pyrolysis and located in biochar pores) or by creating soil conditions more favorable for microbial activity (Domene et al., 2015; Lehmann and Joseph, 2009; Rutigliano et al., 2014; Smith et al., 2010). In studies that found negative effects of biochar on soil respiration, the authors explain this by sorption of soil organic compounds on the biochar surface and consequent decrease of availability of these compounds. Another reason of respiration decrease while maintaining microbial biomass levels may be the high availability of nutrients on the biochar (Lehmann et al., 2011).

The additional increase of microbial respiration in variants $\mathrm{C}$ and $\mathrm{D}$ observed in our experiment may be explained by the introduction of microbes that were specifically isolated to decompose hydrocarbons. Indeed, in these two variants, we observed slightly higher hydrocarbon degradation rates (Fig. 2). Another reason might be the state of microbes introduced. In comparison with indigenous soil microflora that overcomes the lag phase for metabolic activation after the beginning of remediation, immobilized microbes are active and start to function immediately after introduction. Besides, increase of microbial respiration could be caused by massive death of the introduced bacteria, and decomposition of the dead biomass by soil-indigenous microflora.

Changes of metabolic activity of soil microbes may be a result of an altered microbial community structure, and in the process of bioremediation of oil pollution, bacteria play a more important role (Atlas, 1995; Galitskaya et al., 2015a; Qin et al., 2013). That is why, in the next stage of investigation, we estimated the structure of bacterial communities in remediating variants. For analysis, soil was sampled on days 1,28 , and 84 , for the following reasons: days 1 and 84 represent the beginning and the end of remediation, and on day 28 , significant differences in hydrocarbon content between variants $\mathrm{B}-\mathrm{D}$ and $\mathrm{A}$ were observed $(p \leq 0.05)$; apart from this, on day 28, main fluctuations of microbial biomass carbon and respiration ended, indicating the change from an actively functioning microbial community to stabilization.

After sequence filtering and rarefying, there were 156760 high-quality sequences in total from all 12 samples. The average read length was $455 \mathrm{bp}$. Sequence number per sample ranged from 12726 to 13224 . The histogram representing dominating phyla in the remediated variants is shown in Fig. 5. Day 1 in variant A represents the bacterial community in the contaminated soil without any kind of treatment. We found $7 \times 10^{5}$ bacterial $16 \mathrm{~S}$ rDNA copy numbers and 290 OTUs in this variant, and Proteobacteria (mainly gamma and alpha), Actinobacteria, Bacteroidetes, Gemmatimonadetes, and Acidobacteria were the dominating phyla, with $88.86 \%$ abundance in total. On the OTU level, Pseudoxanthomonas sp., Gemm-5 strain, Ectothiorhodospiraceae, Xylanomicrobium, and Marinicellaceae, with $28.27 \%$ in total, dominated. Close relatives of bacteria belonging to the same taxa were previously found in oil-contaminated sites (Abed et al., 2015; Patel et al., 2012), soils (D'haeseleer et al., 2013; Schumann and Stackebrandt, 2014) and sediments with high salt content (Koo et al., 2015).

Aeration and moistening of the contaminated soil (samples A28 and A84) did not lead to changes in bacterial alpha diversity as revealed by simple I, Shannon-Weaver $\mathrm{H}$, and Simpson D indexes presented in Table 2 . However, it slightly increased bacterial copy numbers and altered OTU composition. Thus, the abundance of Bacteroidetes and Acidobacteria increased, while the abundance of Actinobacteria, Gemmatimonadetes, and Proteobacteria decreased. Pseudoxanthomonas sp., Gemm-5 strain, Marinicellaceae, and Xylanomicrobium decreased in abundance, while Ectothiorhodospiraceae remained abundant. Apart from this, several new OTUs became dominant: Bacteroidales, BD7-3 strain, Xanthomonadaceae, LD19 strain, TM7-1 strain, EW055 strain, and Optitus sp. The last three ones, with 24.99 and $15.54 \%$ in total on day 28 and 84, respectively, were described as facultative anaerobic oil-contaminated soil and sediment inhabitants able to degrade hydrocarbons, whereas the LD19 


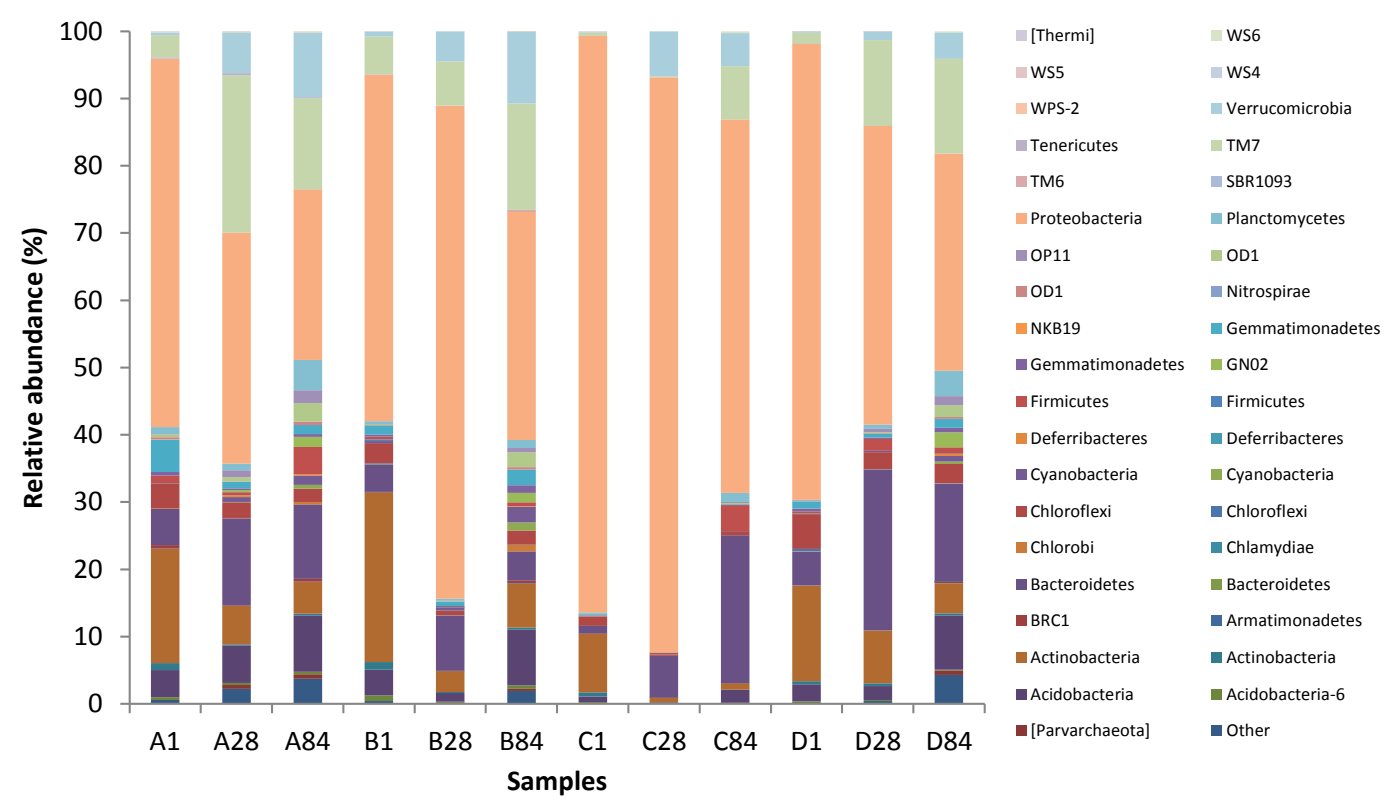

Figure 5. Relative abundance of different phyla in bioremediated soil samples (A, B, C, D - names of the variant, as in Fig. 2; 1, 28, 84 days of sampling).

Table 2. Alpha biodiversity indexes and $16 \mathrm{~S}$ rDNA copy number in bioremediated soil samples.

\begin{tabular}{lllllllllllll}
\hline \multirow{2}{*}{ Parameter } & \multicolumn{10}{c}{ Variant name (letter) and day of sampling (number) } \\
\cline { 2 - 12 } & A1 & A28 & A84 & B1 & B28 & B84 & C1 & C28 & C84 & D1 & D28 & D84 \\
\hline I index & 290 & 270 & 263 & 278 & 230 & 244 & 190 & 151 & 192 & 253 & 281 & 259 \\
H index & 4.251 & 4.009 & 4.250 & 4.277 & 3.809 & 4.013 & 1.533 & 3.061 & 3.534 & 2.958 & 3.840 & 3.937 \\
D index & 0.966 & 0.957 & 0.974 & 0.965 & 0.958 & 0.964 & 0.419 & 0.916 & 0.947 & 0.770 & 0.947 & 0.958 \\
\hline Number of copies & $7 \times 10^{5}$ & $3 \times 10^{6}$ & $2 \times 10^{6}$ & $1 \times 10^{6}$ & $3 \times 10^{6}$ & $3 \times 10^{6}$ & $7 \times 10^{6}$ & $7 \times 10^{6}$ & $5 \times 10^{6}$ & $3 \times 10^{6}$ & $2 \times 10^{6}$ & $2 \times 10^{6}$ \\
\hline
\end{tabular}

strain from the order Methylacidiphilales order is a soilliving methanotroph. Possibly, active consumption of oxygen from hydrocarbon decomposers together with non-sufficient aeration caused by pore occlusion in oil-contaminated soil led to the development of anaerobic hotspots within remediated soil.

In comparison with variant $\mathrm{A}$, the addition of biochar to contaminated soil (samples B1, B28, B84) did not lead to alteration of bacterial counts as revealed by $16 \mathrm{~S}$ rDNA copy number estimation, but caused a slight decrease in bacterial alpha diversity (simple I, Shannon-Weaver H, and Simpson D indexes) (Table 2). In the literature, controversial data about biochar influence on soil microbial community composition have been published; however, in all the cases described, the changes observed were not significant (Khodadad et al., 2011; O'Neill et al., 2009; Rutigliano et al., 2014). This suggests that the effect of biochar is individual in each case and depends on biochar characteristics as well as on initial soil physical and chemical parameters and the original microbial community structure. In our case, biochar addition resulted in an increase of Actinobacteria (day 1) and
Proteobacteria (days 28 and 84), which is in line with data presented by other authors. Thus, Proteobacteria, especially alpha and gamma, were predominant in oil-polluted soils because many proteobacterial species are capable of degrading hydrocarbons. The relative abundance of Actinobacteria usually increases after oil pollution because species belonging to this phylum are known as degraders of recalcitrant organic compounds (Khodadad et al., 2011; Qin et al., 2013; Shahi et al., 2016; Xu et al., 2016). Biochar amendment resulted in the decrease of relative abundance of several bacterial phyla-Gemmatimonadetes (day 1), Chloroflexi and TM7 (day 28), and Bacteroidetes (days 28 and 84). This could be explained by alteration of soil porosity and moisture content caused by biochar. Gemmatimonadetes usually prefer drier conditions, and Chloroflexi are usually effective biodestructors; in our study, their abundance may decrease with substrate exhaustion. TM7 prefer acidic soils with partly anaerobic conditions. The relative abundance of all the taxa mentioned increased and decreased after biochar addition in different studies (Khodadad et al., 2011; Xu et al., 2016). In terms of dominating OTUs, biochar, immediately after addi- 
tion, led to an increase of Nocardioides strain and Xylanimicrobium sp., whereas abundance of the other OTUs decreased or remained stable. OTU abundance was very low on days 28 and 84. Nocardioides strains are able to degrade alkanes as well as polycyclic aromatic compounds (Hamamura and Arp, 2000; Harayama et al., 1999; Vazquez-Duhalt and Quintero-Ramirez, 2004); thus their development might play an important role for intensification of oil degradation after using biochar. Their abundance decreased on day 28, possibly because they finished decomposing the substrate they preferred. Another reason could be the alteration of abiotic factors, growth of other strains in the altered conditions, and competitive exclusion. Several strains were only abundant on day 28: Olivibacter sp., Parvibaculum sp., two Pseudomonadaceae strains, two Sphingopyxis strains, Achromobacter sp., and one Chromatiaceae strain (Table 3). The bacterial community on day 28 reflects the end of active hydrocarbon decomposition in biochar-amended soil. All the bacterial taxa that were abundant at this time were previously described as efficient degraders of hydrocarbons (Abed et al., 2015; Agnello et al., 2015; Cappello et al., 2016; Dashti et al., 2015; Galitskaya et al., 2015b; Kauppi et al., 2011; Shahi et al., 2016). Therefore, we conclude that the higher decomposition rate in variant $B$ is due to the stimulation of degraders by biochar. This may be caused by optimization of oxygen supply or by providing bioavailable compounds that are contained in biochar and may be used for the growth of degrader populations. On day 84 , the relative abundance of OTUs close to those able to degrade hydrocarbons or inhabit oil-polluted soils decreased significantly. In addition, many dominating OTUs were altered. Overall, the list of dominating OTUs was quite similar in A1/B1 and A84/B84 sample pairs, but different in the A28/B28 pair. This corresponds to the hydrocarbon content and microbial parameter dynamics: significant differences after biochar addition were observed during the first month of bioremediation $(p \leq 0.05)$.

Immobilization of hydrocarbon degrader strains $P$. aeroginosa and A. radioresistens - on biochar significantly altered the microbial community of soil after biochar addition $(p \leq 0.05)$. As expected, these strains were highly dominant - with 76.08 and $47.16 \%$ in C1 and D1 samples, respectively. The second abundant OTU in both samples was Pseudoxanthomonas sp., which dominated A1 and B1 samples (Table 3). In comparison with the A1 sample, after addition of biochar with immobilized microbes, bacterial copy numbers raised about 10 and 4 times in C1 and D1 samples, respectively. Strong domination of only one strain led to a significant decrease of alpha biodiversity in both $\mathrm{C} 1$ and D1 samples, while this effect was more pronounced in the first one (Table 2). The number of strains in the $\mathrm{C} 1$ sample was 1.92 times lower, and the Shannon-Weaver index was 2.77 lower than in the A1 sample.

The dynamics of bacterial communities in $\mathrm{C}$ and $\mathrm{D}$ variants showed several common trends. Thus, neither $P$. putida nor $A$. radioresistens added to soil on biochar dominated in the corresponding bacterial communities on days 28 and 84 . Proteobacteria (including dominating strains) was the dominating phyla in both soils after addition of biochar with immobilized microbes at all sampling times. Actinobacteria was second abundant on day 1 in both $\mathrm{C} 1$ and D1, but its amount decreased over time. In contrast, abundance of $\mathrm{Bac}$ teroidetes and TM7 phyla increased over time in both variants. In comparison with variants $\mathrm{A}$ and $\mathrm{B}$, in both variants $\mathrm{C}$ and D, two new dominating OTUs were observed: one OTU representing the family Porphyromonadaceae and one representing Alcanivorax sp (in C2, D2, and D3 samples). Members of the family Porphyromonadaceae are usually anaerobic sugar-fermenting bacteria. As in the case of variant A, anaerobic species may grow in bioremediated aerated soil because of the high oxygen demand of other microbes. $\mathrm{Al}$ canivorax $s p$. was described previously as a species that inhabits oil-polluted soil and as a degrader of aliphatic hydrocarbons. Its abundance increases during biostimulation.

However, dynamics of bacterial community composition in variants $\mathrm{C}$ and $\mathrm{D}$ were not similar. Differences between these communities as well as between those in variants $\mathrm{A}$ and $\mathrm{B}$ are presented in the MDS plot in Fig. 6 .

As shown in the plot, dots representing bacterial communities may be grouped according to sampling days. This means that contaminated soil properties and initial microbial composition play a major role in community dynamics during bioremediation, while biochar addition as well as the introduction of microbes on biochar are less important. Dots representing bacterial communities on day 28 are situated further away from each other than those sampled on days 1 and 84, suggesting that biochar and introduced microbes altered the initial microbial community structure mainly during the first month of bioremediation. This corresponds to the differences in hydrocarbon content and microbial parameters that were higher in the first month. Variant $\mathrm{C}$ differed from the other variants on all sampling dates; this may be explained by the higher concentration of $P$. putida cells that was introduced. Interestingly, variant $\mathrm{C}$ was different from the others on days 28 and 84 , despite the fact that counts of introduced bacteria decreased. This may be because introduced bacteria significantly altered the abundance of the other species.

Hydrocarbon-polluted soil is toxic for plants, possibly due to direct inhibiting effects of hydrocarbons or their metabolites as well as to changed soil conditions (Al-Mutairi et al., 2008; Morelli et al., 2005; Tahhan and Abu-Ateih, 2009). Apart from this, oil pollution may lead to changes of the microbial community structure, favoring the dominance of phytotoxin-producing species (Labud et al., 2007; Steliga et al., 2012). In the literature, phytotoxicity estimation is often recommended to control the efficiency of remediation measures as well as to access biochar quality (Labud et al., 2007; Morelli et al., 2005; Steliga et al., 2012). Fig. 7 shows the results of phytotoxicity estimation in the remediated soil expressed as GI. 


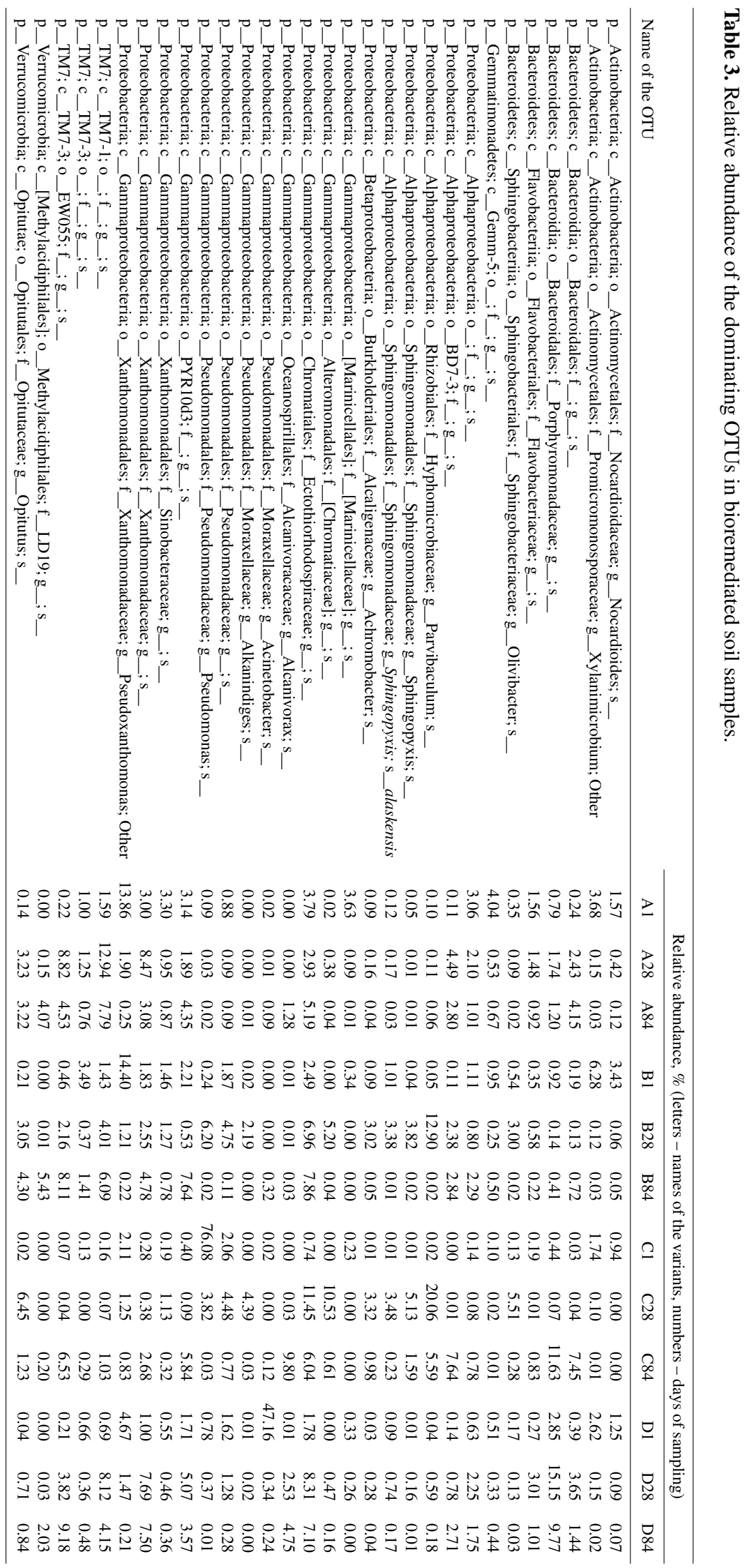




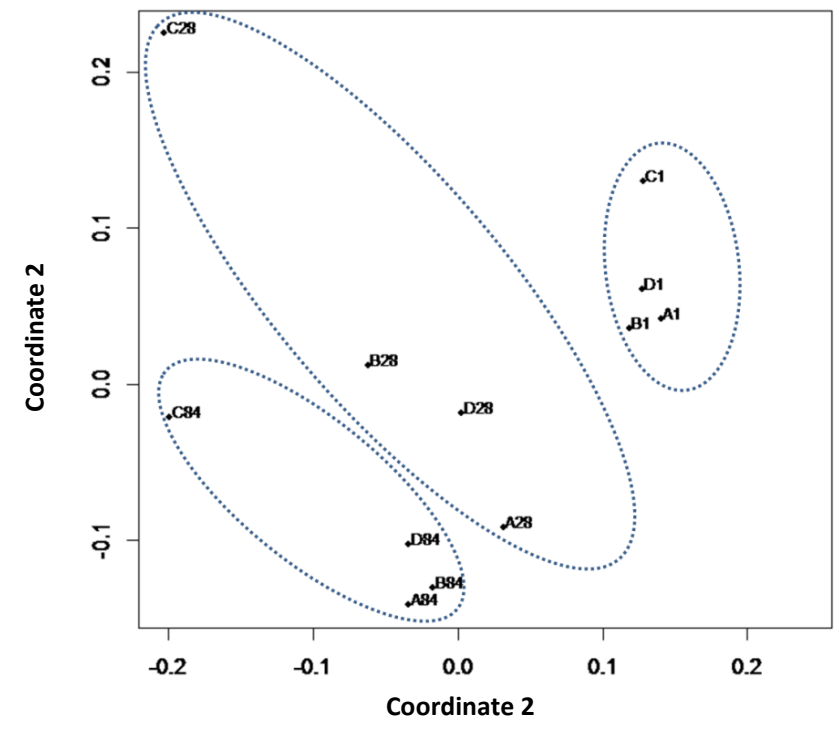

Figure 6. Metric multidimensional scaling analysis based on distance matrix of OTU relative abundance in bioremediated soil samples (A, B, C, D - names of the variants, as in Fig. 2; 1, 28, 84 - days of sampling).

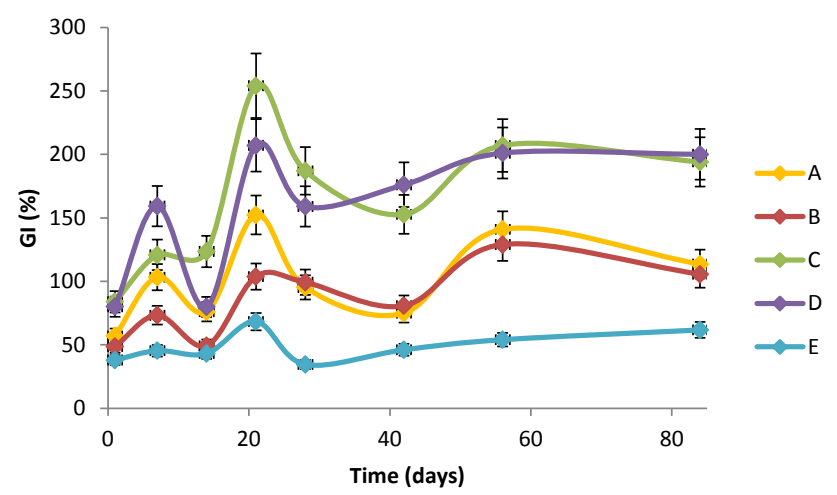

Figure 7. Changes of phytotoxicity in the remediated soil (A, B, C, D, E - as in Fig. 2).

GI level in variant $\mathrm{E}$ (control) was consistently low during the whole experiment (38-68\%), whereas GI values in the other variants increased during bioremediation. At the end of the study, GI was estimated to be $205 \%$ in variants C and D and $110 \%$ in variants $\mathrm{A}$ and $\mathrm{B}$.

The difference between the two pairs of variants already appeared at the beginning of remediation, when GI in variants $\mathrm{C}$ and $\mathrm{D}$ increased more rapidly compared to variants $\mathrm{A}$ and B. After day $1, \mathrm{GI}$ in variants $\mathrm{C}$ and $\mathrm{D}$ was about 1.7 -fold higher and further increased significantly. Notably, respiration activity in variants $\mathrm{C}$ and $\mathrm{D}$ was higher than in the other variants at that time (Fig. 4), whereas hydrocarbon decomposition was more intensive in variants $\mathrm{B}, \mathrm{C}$, and $\mathrm{D}$ as compared to variant $\mathrm{A}$ (Fig. 2). Possibly, aeration and moistening in variant $\mathrm{A}$ and biochar addition in variant $\mathrm{B}$ only stimu- lated hydrocarbon degraders that were present in the soil microbial pool, while the biochar addition effect was more pronounced. Addition of active hydrocarbon decomposers, such as $P$. aeruginosa and $A$. radioresistens with several enzymes for different metabolic pathways of hydrocarbon degradation (Agnello et al., 2015; Atlas, 1995), altered the process of oxidation into full oxidation direction with $\mathrm{CO}_{2}$ as the final product. The introduced strains consumed both initial hydrocarbons and metabolites of degradation produced by the soil microflora, which resulted in a significant increment of microbial respiration against the background of a slight increment of initial hydrocarbon decomposition.

\section{Conclusion}

Amendment of oil-polluted soil by biochar causes acceleration of hydrocarbon decomposition as compared with remediation by means of mixing and moistening. This may be caused by stimulation of microorganisms able to degrade hydrocarbons due to alteration of soil conditions or due to providing them with nutrients present in the biochar. From a practical point of view, this acceleration may be useful in regions where remediation time is limited (e.g., regions with a cold climate). Immobilization of hydrocarbon degraders leads to an additional effect of biochar on soil phytotoxicity and microbial respiration. This may be due to differences of metabolic pathways of introduced and indigenous microbes. Bioaugmentation may be recommended as an additional tool of remediation used in combination with biochar. All the strategies of bioremediation used caused changes in the bacterial community structure. However, as revealed by MDS analysis, differences between the communities were higher at different sampling times as compared with different remediation variants. This suggests that initial bacterial composition is a main factor that influences changes that the bacterial community overcomes during bioremediation.

\section{The Supplement related to this article is available online at doi:10.5194/bg-13-5739-2016-supplement.}

Acknowledgements. The work is performed according to the Russian Government Program of Competitive Growth of Kazan Federal University. The research was performed using the equipment of Interdisciplinary Center for Shared Use of Kazan Federal University. Tatiana Grigoryeva's help with the sequencing is gratefully acknowledged. In addition, the time and effort of the anonymous reviewers, who contributed to improvement of the article, are gratefully acknowledged.

Edited by: Y. Kuzyakov

Reviewed by: B. Guenet and one anonymous referee 


\section{References}

Abed, R. M. M., Al-Kharusi, S., and Al-Hinai, M.: Effect of biostimulation, temperature and salinity on respiration activities and bacterial community composition in an oil polluted desert soil, Int. Biodeter. Biodegr., 98, 43-52, doi:10.1016/j.ibiod.2014.11.018, 2015.

Agnello, A. C., Bagard, M., van Hullebusch, E. D., Esposito, G., and Huguenot, D.: Comparative bioremediation of heavy metals and petroleum hydrocarbons co-contaminated soil by natural attenuation, phytoremediation, bioaugmentation and bioaugmentationassisted phytoremediation., Sci. Total Environ., 563-564, 693703, doi:10.1016/j.scitotenv.2015.10.061, 2015.

Alexander, M.: How toxic are toxic chemicals in soil?, Environ. Sci. Technol., 29, 2713-2717, 1995.

Al-Mutairi, N., Bufarsan, A., and Al-Rukaibi, F.: Ecorisk evaluation and treatability potential of soils contaminated with petroleum hydrocarbon-based fuels, Chemosphere, 74, 142-148, doi:10.1016/j.chemosphere.2008.08.020, 2008.

Atlas, R. M.: Petroleum biodegradation and oil spill bioremediation, Mar. Pollut. Bull., 31, 178-182, doi:10.1016/0025326X(95)00113-2, 1995.

Awad, Y. M., Blagodatskaya, E., Ok, Y. S., and Kuzyakov, Y.: Effects of polyacrylamide, biopolymer, and biochar on decomposition of soil organic matter and plant residues as determined by $14 \mathrm{C}$ and enzyme activities, Eur. J. Soil Biol., 48, 1-10, doi:10.1016/j.ejsobi.2011.09.005, 2012.

Beesley, L., Moreno-Jiménez, E., Gomez-Eyles, J. L., MorenoJiménez, E., and Gomez-Eyles, J. L.: Effects of biochar and greenwaste compost amendments on mobility, bioavailability and toxicity of inorganic and organic contaminants in a multi-element polluted soil, Environ. Pollut., 158, 2282-2287, doi:10.1016/j.envpol.2010.02.003, 2010.

Beesley, L., Moreno-Jiménez, E., Gomez-Eyles, J. L., Harris, E., Robinson, B., and Sizmur, T.: A review of biochars' potential role in the remediation, revegetation and restoration of contaminated soils, Environ. Pollut., 159, 3269-3282, doi:10.1016/j.envpol.2011.07.023, 2011.

Beškoski, V. P., Gojgić-Cvijović, G., Milić, J., Ilić, M., Miletić, S., Šolević, T., and Vrvić, M. M.: Ex situ bioremediation of a soil contaminated by mazut (heavy residual fuel oil) - A field experiment, Chemosphere, 83, 34-40, doi:10.1016/j.chemosphere.2011.01.020, 2011.

Bhaduri, D., Saha, A., Desai, D., and Meena, H. N.: Restoration of carbon and microbial activity in saltinduced soil by application of peanut shell biochar during short-term incubation study, Chemosphere, 148, 86-98, doi:10.1016/j.chemosphere.2015.12.130, 2016.

Butnan, S., Deenik, J. L., Toomsan, B., Antal, M. J., and Vityakon, P.: Biochar characteristics and application rates affecting corn growth and properties of soils contrasting in texture and mineralogy, Geoderma, 237, 105-116, doi:10.1016/j.geoderma.2014.08.010, 2015.

Caporaso, J. G., Kuczynski, J., Stombaugh, J., Bittinger, K., Bushman, F. D., Costello, E. K., Fierer, N., Peña, A. G., Goodrich, K., Gordon, J. I., Huttley, G. A., Kelley, S. T., Knights, D., Jeremy, E., Ley, R. E., Lozupone, C. A., Mcdonald, D., Muegge, B. D., Reeder, J., Sevinsky, J. R., Turnbaugh, P. J., and Walters, W. a: QIIME allows analysis of high-throughput community sequenc- ing data, Nat. Methods, 7, 335-336, doi:10.1038/nmeth.f.303, 2010.

Cappello, S., Volta, A., Santisi, S., and Torregrossa, M.: Oildegrading bacteria from a membrane bioreactor (BF-MBR) system for treatment of saline oily waste: Isolation, identification and characterization of the biotechnological potential, Int. Biodeter. Biodegr., 110, 235-244, 2016.

Chan, K., Van Zwieten, L., Meszaros, I., Downie, A., and Joseph, S.: Using poultry litter biochars as soil amendments, Soil Res., 46, 437-444, 2008.

Dashti, N., Ali, N., Khanafer, M., Al-Awadhi, H., Sorkhoh, N., and Radwan, S.: Olive-pomace harbors bacteria with the potential for hydrocarbon-biodegradation, nitrogenfixation and mercury-resistance: Promising material for waste-oil-bioremediation, J. Environ. Manage., 155, 49-57, doi:10.1016/j.jenvman.2015.03.010, 2015.

Demisie, W., Liu, Z., and Zhang, M.: Catena Effect of biochar on carbon fractions and enzyme activity of red soil, Catena, 121, 214-221, doi:10.1016/j.catena.2014.05.020, 2014.

D'haeseleer, P., Gladden, J. M., Allgaier, M., Chain, P. S. G., Tringe, S. G., Malfatti, S. A., Aldrich, J. T., Nicora, C. D., Robinson, E. W., Paša-Tolić, L., Hugenholtz, P., Simmons, B. A., and Singer, S. W.: Proteogenomic Analysis of a Thermophilic Bacterial Consortium Adapted to Deconstruct Switchgrass, edited by: Xu, Y., PLoS One, 8, doi:10.1371/journal.pone.0068465, 2013.

Domene, X., Enders, A., Hanley, K., and Lehmann, J.: Ecotoxicological characterization of biochars: Role of feedstock and pyrolysis temperature, Sci. Total Environ., 512-513, 552-561, doi:10.1016/j.scitotenv.2014.12.035, 2015.

Durenkamp, M., Luo, Y., and Brookes, P. C.: Impact of black carbon addition to soil on the determination of soil microbial biomass by fumigation extraction, Soil Biol. Biochem., 42, 2026-2029, doi:10.1016/j.soilbio.2010.07.016, 2010.

Edgar, R. C.: Search and clustering orders of magnitude faster than BLAST, Bioinformatics, 26, 2460-2461, 2010.

Faith, D. P., Minchin, P. R., and Belbin, L.: Compositional dissimilarity as a robust measure of ecological distance, Vegetatio, 69, 57-68, 1987.

Galitskaya, P., Gumerova, R., Ratering, S., Schnell, S., Blagodatskaya, E., and Selivanovskaya, S.: Oily waste containing natural radionuclides: Does it cause stimulation or inhibition of soil bacterial community?, J. Plant Nutr. Soil Sc., 178, 825-833, doi:10.1002/jpln.201400641, 2015a.

Galitskaya, P., Biktasheva, L., Saveliev, A., Ratering, S., Schnell, S., and Selivanovskaya, S.: Response of soil microorganisms to radioactive oil waste: results from a leaching experiment, Biogeosciences, 12, 3681-3693, doi:10.5194/bg-12-3681-2015, 2015 b.

Gumerova, R. K., Selivanovskaya, S. Y., and Galitskaya, P. Y.: Changes of hydrocarbon and oil fractions in oily waste treated by different methods of bioremediation, Neft. Khoz., 9, 118-120, 2013.

Hamamura, N. and Arp, D. J.: Isolation and characterization of alkane-utilizing Nocardioides sp. strain CF8, FEMS Microbiol. Lett., 186, 21-26, doi:10.1016/S0378-1097(00)00109-9, 2000.

Harayama, S., Kishira, H., Kasai, Y., and Shutsubo, K.: Petroleum Biodegradation in Marine Environments, Molec. Microbiol. Biotechnol, 1, 63-70, 1999.

ISO 14240-2: Soil quality - Determination of soil microbial biomass - Part 2: Fumigation-extraction method, 10 p., 1998. 
ISO 16072: Soil quality - Laboratory methods for determination of microbial soil respiration, 19 pp., 2002.

ISO 11269-1: Soil quality - Determination of the effects of pollutants on soil flora - Part 1: Method for the measurement of inhibition of root growth, 2012.

ISO 11269-2: Soil quality - Determination of the effects of pollutants on soil flora - Part 2: Effects of contaminated soil on the emergence and early growth of higher plants, 2012.

Jones, D. L., Rousk, J., Edwards-Jones, G., DeLuca, T. H., and Murphy, D. V.: Biochar-mediated changes in soil quality and plant growth in a three year field trial, Soil Biol. Biochem., 45, 113124, doi:10.1016/j.soilbio.2011.10.012, 2012.

Jørgensen, K. S., Puustinen, J., and Suortti, A. M.: Bioremediation of petroleum hydrocarbon-contaminated soil by composting in biopiles, Environ. Pollut., 107, 245-254, 2000.

Kauppi, S., Sinkkonen, A., and Romantschuk, M.: Enhancing bioremediation of diesel-fuel-contaminated soil in a boreal climate: Comparison of biostimulation and bioaugmentation, Int. Biodeter. Biodegr., 65, 359-368, doi:10.1016/j.ibiod.2010.10.011, 2011

Khodadad, C. L. M., Zimmerman, A. R., Green, S. J., Uthandi, S., and Foster, J. S.: Taxa-specific changes in soil microbial community composition induced by pyrogenic carbon amendments, Soil Biol. Biochem., 43, 385-392, doi:10.1016/j.soilbio.2010.11.005, 2011

Koo, H., Mojib, N., Huang, J. P., Donahoe, R. J., and Bej, A. K.: Bacterial community shift in the coastal Gulf of Mexico saltmarsh sediment microcosm in vitro following exposure to the Mississippi Canyon Block 252 oil (MC252), 3 Biotech, 5, 379392, doi:10.1007/s13205-014-0233-x, 2015.

Kuppusamy, S., Thavamani, P., Megharaj, M., Venkateswarlu, K., and Naidu, R.: Agronomic and remedial benefits and risks of applying biochar to soil: Current knowledge and future research directions, Environ. Int., 87, 1-12, doi:10.1016/j.envint.2015.10.018, 2016.

Kuśmierz, M., Oleszczuk, P., Kraska, P., Pałys, E., and Andruszczak, S.: Persistence of polycyclic aromatic hydrocarbons (PAHs) in biochar-amended soil, Chemosphere, 146, 272-279, doi:10.1016/j.chemosphere.2015.12.010, 2016.

Kuzyakov, Y., Subbotina, I., Chen, H., Bogomolova, I., and Xu, X.: Black carbon decomposition and incorporation into soil microbial biomass estimated by 14C labeling, Soil Biol. Biochem., 41, 210-219, doi:10.1016/j.soilbio.2008.10.016, 2009.

Labud, V., Garcia, C., and Hernandez, T.: Effect of hydrocarbon pollution on the microbial properties of a sandy and a clay soil, Chemosphere, 66, 1863-1871, doi:10.1016/j.chemosphere.2006.08.021, 2007.

Lehmann, J. and Joseph, S.: Biochar for environmentalmanagement: an introduction, in: Biochar for Environmental Management: Science and Technology, edited by: Lehmann, J. and Joseph, S., Earthscan, London, UK, 2009.

Lehmann, J., Rillig, M. C., Thies, J., Masiello, C. A., Hockaday, W. C., and Crowley, D.: Biochar effects on soil biota - A review, Soil Biol. Biochem., 43, 1812-1836, doi:10.1016/j.soilbio.2011.04.022, 2011.

Liu, W., Luo, Y., Teng, Y., Li, Z., and Christie, P.: Prepared bed bioremediation of oily sludge in an oilfield in northern China, J. Hazard. Mater., 161, 479-484, doi:10.1016/j.jhazmat.2008.03.123, 2009.
Liu, X., Zheng, J., Zhang, D., Cheng, K., Zhou, H., Zhang, A., Li, L., Joseph, S., Smith, P., Crowley, D., Kuzyakov, Y., and Pan, G.: Biochar has no effect on soil respiration across Chinese agricultural soils, Sci. Total Environ., 554, 259-265, doi:10.1016/j.scitotenv.2016.02.179, 2016.

Lu, H., Li, Z., Fu, S., Méndez, A., Gascó, G., and Paz-Ferreiro, J.: Combining phytoextraction and biochar addition improves soil biochemical properties in a soil contaminated with $\mathrm{Cd}$, Chemosphere, 119, 209-216, doi:10.1016/j.chemosphere.2014.06.024, 2015.

Marin, J. A., Hernandez, T., and Garcia, C.: Bioremediation of oil refinery sludge by landfarming in semiarid conditions: Influence on soil microbial activity, Environ. Res., 98, 185-195, doi:10.1016/j.envres.2004.06.005, 2005.

Morelli, I. S., Del Panno, M. T., De Antoni, G. L., and Painceira, M. T.: Laboratory study on the bioremediation of petrochemical sludge-contaminated soil, Int. Biodeter. Biodegrad., 55, $271-$ 278, 2005.

Nikolopoulou, M., Pasadakis, N., and Kalogerakis, N.: Evaluation of autochthonous bioaugmentation and biostimulation during microcosm-simulated oil spills, Mar. Pollut. Bull., 72, 165173, doi:10.1016/j.marpolbul.2013.04.007, 2013.

O’Neill, B., Grossman, J., Tsai, M. T., Gomes, J. E., Lehmann, J., Peterson, J., Neves, E., and Thies, J. E.: Bacterial community composition in Brazilian Anthrosols and adjacent soils characterized using culturing and molecular identification, Microb. Ecol., 58, 23-35, 2009.

Patel, V., Cheturvedula, S., and Madamwar, D.: Phenanthrene degradation by Pseudoxanthomonas sp. DMVP2 isolated from hydrocarbon contaminated sediment of Amlakhadi canal, Gujarat, India., J. Hazard. Mater., 201-202, 43-51, doi:10.1016/j.jhazmat.2011.11.002, 2012.

Qin, G., Gong, D., and Fan, M. Y.: Bioremediation of petroleum-contaminated soil by biostimulation amended with biochar, Int. Biodeter. Biodegr., 85, 150-155, doi:10.1016/j.ibiod.2013.07.004, 2013.

Quilliam, R. S., Glanville, H. C., Wade, S. C., and Jones, D. L.: Life in the "charosphere" - Does biochar in agricultural soil provide a significant habitat for microorganisms?, Soil Biol. Biochem., 65, 287-293, doi:10.1016/j.soilbio.2013.06.004, 2013.

R Core Development Team: R: a language and environment for statistical computing, 3.2.1, available at: http://www.r-project.org, doi:10.1017/CBO9781107415324.004, 2015.

Rocha, L. L., Colares, G. B., Angelim, A. L., Grangeiro, T. B., and Melo, V. M. M.: Culturable populations of Acinetobacter can promptly respond to contamination by alkanes in mangrove sediments, Mar. Pollut. Bull., 76, 214-219, doi:10.1016/j.marpolbul.2013.08.040, 2013.

Ros, M., Rodríguez, I., García, C., and Hernández, T.: Microbial communities involved in the bioremediation of an aged recalcitrant hydrocarbon polluted soil by using organic amendments, Bioresource Technol., 101, 6916-6923, doi:10.1016/j.biortech.2010.03.126, 2010.

Rutigliano, F. A., Romano, M., Marzaioli, R., Baglivo, I., Baronti, S., Miglietta, F., and Castaldi, S.: Effect of biochar addition on soil microbial community in a wheat crop, Eur. J. Soil Biol., 60, 9-15, doi:10.1016/j.ejsobi.2013.10.007, 2014.

Schumann, P. and Stackebrandt, E.: The Family Promicromonosporaceae, in: The Prokaryotes: Actinobacteria, edited by: Rosen- 
berg, E., DeLong, E. F., Lory, S., Stackebrandt,E., and Thompson, F., 701-724, Springer Berlin Heidelberg, Germany, 2014.

Selivanovskaya, S. Y., Kuritsin, I. N., Akhmetzyanova, L. G., Galitskaya, P. Y., and Solovjev, D. A.: Use of biological activity index for determination of oil polluted area meant for remediation, Neft. Khoz., 6, 102-103, 2012.

Shahi, A., Aydin, S., Ince, B., and Ince, O.: Evaluation of microbial population and functional genes during the bioremediation of petroleum-contaminated soil as an effective monitoring approach, Ecotox. Environ. Safe., 125, 153-160, doi:10.1016/j.ecoenv.2015.11.029, 2016.

Shannon, C. E. and Weaver, W.: The mathematical theory of communication, University of Illinois Press, Urbana, IL, USA, 1963.

Simpson, E. H.: Measurement of diversity, Nature, 163, p. 688, 1949.

Smith, J. L., Collins, H. P., and Bailey, V. L.: The effect of young biochar on soil respiration, Soil Biol. Biochem., 42, 2345-2347, doi:10.1016/j.soilbio.2010.09.013, 2010.

Steliga, T., Jakubowicz, P., and Kapusta, P.: Changes in toxicity during in situ bioremediation of weathered drill wastes contaminated with petroleum hydrocarbons, Bioresource Technol., 125, 1-10, 2012.

Suja, F., Rahim, F., Raihan, M., Hambali, N., Razali, M. R., Khalid, A., and Hamzah, A.: International Biodeterioration \& Biodegradation Effects of local microbial bioaugmentation and biostimulation on the bioremediation of total petroleum hydrocarbons (TPH) in crude oil contaminated soil based on laboratory and fi eld observations, Int. Biodeter. Biodegr., 90, 115-122, doi:10.1016/j.ibiod.2014.03.006, 2014.

Taccari, M., Milanovic, V., Comitini, F., Casucci, C., and Ciani, M.: Effects of biostimulation and bioaugmentation on diesel removal and bacterial community, Int. Biodeter. Biodegr., 66, 3946, doi:10.1016/j.ibiod.2011.09.012, 2012.

Tahhan, R. A. and Abu-Ateih, R. Y.: Biodegradation of petroleum industry oily-sludge using Jordanian oil refinery contaminated soil, Int. Biodeter. Biodegr., 63, 1054-1060, doi:10.1016/j.ibiod.2009.09.001, 2009.

Tahhan, R. A., Ammari, T. G., Goussous, S. J., and AlShdaifat, H. I.: Enhancing the biodegradation of total petroleum hydrocarbons in oily sludge by a modified bioaugmentation strategy, Int. Biodeter. Biodegr., 65, 130-134, doi:10.1016/j.ibiod.2010.09.007, 2011.
Tang, J., Wang, R., Niu, X., and Zhou, Q.: Enhancement of soil petroleum remediation by using a combination of ryegrass (Lolium perenne) and different microorganisms, Soil Till. Res., 110, 87-93, doi:10.1016/j.still.2010.06.010, 2010.

Tang, J., Wang, M., Wang, F., Sun, Q., and Zhou, Q.: Eco-toxicity of petroleum hydrocarbon contaminated soil, J. Environ. Sci., 23, 845-851, doi:10.1016/S1001-0742(10)60517-7, 2011.

Tang, J., Lu, X., Sun, Q., and Zhu, W.: Aging effect of petroleum hydrocarbons in soil under different attenuation conditions, Agr. Ecosyst. Environ., 149, 109-117, doi:10.1016/j.agee.2011.12.020, 2012.

Tang, J., Zhu, W., Kookana, R., and Katayama, A.: Characteristics of biochar and its application in remediation of contaminated soil, J. Biosci. Bioeng., 116, 653-659, doi:10.1016/j.jbiosc.2013.05.035, 2013.

Tejada, M., Gonzalez, J. L., Hernandez, M. T., and Garcia, C.: Application of different organic amendments in a gasoline contaminated soil: Effect on soil microbial properties, Bioresource Technol., 99, 2872-2880, doi:10.1016/j.biortech.2007.06.002, 2008.

Vazquez-Duhalt, R. and Quintero-Ramirez, R.: Petroleum Biotechnology: Developments and Perspectives, edited by: VazquezDuhalt, R. and Quintero-Ramirez, R., Elsevier B.V., Amsterdam, the Netherlands, 2004.

Wang, Q., Garrity, G. M., Tiedje, J. M., and Cole, J. R.: Naive bayesian classifier for rapid assignment of rRNA sequences into the new bacterial taxonomy, Appl. Environ. Microb., 73, 52-61, 2007.

Wang, X., Song, D., Liang, G., Zhang, Q., Ai, C., and Zhou, W.: Maize biochar addition rate influences soil enzyme activity and microbial community composition in a fluvo-aquic soil, Appl. Soil Ecol., 96, 265-272, doi:10.1016/j.apsoil.2015.08.018, 2015.

Wu, M., Dick, W. A., Li, W., Wang, X., Yang, Q., Wang, T., Xu, L., Zhang, M., and Chen, L.: Bioaugmentation and biostimulation of hydrocarbon degradation and the microbial community in a petroleum-contaminated soil, Int. Biodeter. Biodegr., 107, 158164, doi:10.1016/j.ibiod.2015.11.019, 2016.

Xu, N., Tan, G., Wang, H., and Gai, X.: Effect of biochar additions to soil on nitrogen leaching, microbial biomass and bacterial community structure, Eur. J. Soil Biol., 74, 1-8, doi:10.1016/j.ejsobi.2016.02.004, 2016.

Zucconi, F., Pera, A., Forte, M., and de Bertoldi, M.: Evaluating toxicity of immature compost, Biocycle, 22, 54-57, 1981. 